Check for updates

Cite this: Mater. Adv., 2020, 1,666

Received 6th February 2020, Accepted 21st May 2020

DOI: 10.1039/d0ma00007h

rsc.li/materials-advances

\section{Triphenylamine-imidazole-based luminophores for deep-blue organic light-emitting diodes: experimental and theoretical investigations $\dagger$}

\author{
Jairam Tagare, ${ }^{a}$ Deepak Kumar Dubey, ${ }^{\mathrm{b}}$ Rohit Ashok Kumar Yadav, ${ }^{\mathrm{b}}$ \\ Jwo-Huei Jou (D ${ }^{b}$ and Sivakumar Vaidyanathan (D) *a
}

\begin{abstract}
In this paper, three deep blue donor-acceptor (D-A) luminophores with triphenylamine as the holetransporting system and imidazole as the electron-transporting system were synthesized by a condensation reaction and characterized by spectroscopic methods. The detailed thermal, optical, electrochemical and electroluminescence properties were systematically investigated. The synthesized luminophores exhibited good thermal stability and a good photoluminescence quantum yield (PLQY). The ultraviolet-visible (UV-vis) spectra of the luminophores showed multiple absorption bands (UV to near UV region, due to the $\pi-\pi^{\star}$ transitions of the aromatic segments). All the luminophores exhibited blue emission in a dichloromethane (DCM) solution. Solution-processable OLEDs were fabricated by using these luminophores as an emitting dopant in the 4,4'-bis $(9 H$-carbazol-9-yl)biphenyl host and they were found to exhibit bright deep blue electroluminescence (EL). Among these luminophores, the one donor-two acceptor (DBIPTPA) luminophore displayed promising deep blue emission characteristics with more than $100 \%$ color saturation when compared with the National Television System Committee (NTSC) standard. The device fabricated using DBIPTPA showed a high luminance of $495 \mathrm{~cd} \mathrm{~m}^{-2}$ and $2.5 \%$ external quantum efficiency with the CIE coordinate of $(0.16,0.06)$ at the brightness of $100 \mathrm{~cd} \mathrm{~m}^{-2}$.
\end{abstract}

\section{Introduction}

The development of efficient materials has received tremendous impetus in recent years because of various applications in optoelectronic devices such as organic light-emitting diodes (OLEDs), ${ }^{1}$ photovoltaics (OPVs), ${ }^{2}$ non-linear optics (NLOs), ${ }^{3}$ organic field-effect transistors (OFETs), ${ }^{4}$ and molecular sensors. ${ }^{5}$ Recently, OLEDs have drawn significant attention due to their potential utility in the next-generation flat panel displays and solid-state lighting sources. ${ }^{1}$ Many efforts have been made by academics, industries, and research communities to obtain high-efficiency and long-lifespan wet- and dry-process feasible organic materials. ${ }^{6} \mathrm{~A}$ variety of organic materials such as small molecules, ${ }^{1,7}$ dendrimers ${ }^{8}$ and polymers ${ }^{9}$ are already utilized for OLED applications. Among these materials, small

\footnotetext{
${ }^{a}$ Optoelectronics laboratory, Department of Chemistry, National Institute of Technology Rourkela, India. E-mail: vsiva@nitrkl.ac.in; Tel: +91-661-2462654

${ }^{b}$ Department of Materials Science and Engineering, National Tsing Hua University, Hsinchu-30013, Taiwan

$\dagger$ Electronic supplementary information (ESI) available: NMR spectra, mass spectra and IR spectra of the luminophores, the CIE chromaticity coordinates for the luminophores in solutions and solid phase, quantum yield studies of luminophores in solution and solid state, and atom coordinates of all the luminophores. See DOI: 10.1039/d0ma00007h
}

molecules dominate because of their ordered molecular structures, reproducible synthetic procedures, easy purification methods, processability in solution and vacuum deposition methods, and malleable control on the functional properties with simple structural modifications. ${ }^{1}$ It is mandatory to have red, green and blue (RGB) as primary colors to get a full-color display. ${ }^{10}$ Many red and green OLEDs with excellent performance have been reported. However, obtaining stable deepblue OLEDs is still difficult because of the poor carrier injection into the emissive layer due to the intrinsic wide band gap. ${ }^{11}$ The construction of deep-blue emitting materials with a Commission Internationale de l'Eclairage (CIE) coordinate $y<0.10$ (which has been improved to $y<0.06$ by the European Broadcasting Union (EBU)) remains a major challenge. ${ }^{12}$ Hence, there is a necessity for the development of deep blue emitters for full-color displays as one of the three primary colors (RGB) and also as the host for green and red triplet emitters.

Triphenylamine is one of the fruitful structural entities explored by material chemists because it acts as a propitious structure for the construction of molecular materials due to its rigid molecular structure, high thermal, photochemical and morphological stabilities, and better hole-transporting capability via the radical cation species. ${ }^{13}$ Its high triplet energy level $(3.04 \mathrm{eV})$ makes it suitable as a host material in 
phosphorescent OLEDs. ${ }^{14}$ Additionally, triphenylamine derivatives allow efficient hole injection because they have the highest occupied molecular orbital (HOMO) energy level (ca. $5.3 \mathrm{eV}$ ) than carbazole derivatives, which is close to the indium tin oxide (ITO) work function or the value for a commonly used hole transporting material $N, N^{\prime}$-di(1-naphthyl)- $N, N^{\prime}$-diphenyl(1,1'-biphenyl)-4, $4^{\prime}$-diamine (NPB). ${ }^{15}$

Recently, imidazole derivatives such as phenanthroimidazole and diphenylimidazole have been used to generate deep-blue lightemitting devices. ${ }^{16}$ Imidazole when combined with triphenylamine (TPA) serves as an effective bipolar material. ${ }^{17}$ Imidazole derivatives are being widely used because of their wide absorption, bright luminescence, and good bipolar transport characteristics. Hence, there is notable interest in the design and synthesis of imidazoles with enriched functional chromophores to improve their optical and charge transport properties. Encouraged with this concept, we have designed and synthesized one donor-one acceptor (BIPTPA), one donor-two acceptor (DBIPTPA) and one donor-three acceptor (TBIPTPA) luminophores, where the donor refers to the electron-donating moiety and the acceptor refers to the electron-withdrawing moiety. Here, we have chosen triphenylamine as the donor and imidazole as the acceptor to obtain bipolar transport characteristics in the luminophores. All the luminophores were structurally characterized by spectroscopic methods. The photophysical properties of the luminophores varied according to the substitution pattern of the imidazole moiety in the triphenylamine core. DFT computational calculations were also performed to obtain reciprocity among the optical properties and electronic structures of the luminophores. Furthermore, the electroluminescence characteristics of these luminophores were examined by using them as deep-blue emitting dopants in solutionprocessable multilayer OLEDs. Devices containing the BIPTPA and DBIPTPA emitters showed bright deep-blue emission with peaks at 400-420 $\mathrm{nm}$ and Commission International de l'E'clairage coordinates (CIEs) of $0.16<x<0.17$ and $0.06<y<0.07(x, y)$, whereas the device with TBIPTPA as the emitter showed sky-blue emission with the CIE coordinate of $(0.20 \pm 0.01,0.19 \pm 0.02)$ at the brightness of $100 \mathrm{~cd} \mathrm{~m}^{-2}$.

\section{Experimental section}

\section{Synthesis and characterization}

The different aldehyde substrates were synthesized according to a previously reported method. ${ }^{18}$ The targeted BIPTPA, DBIPTPA, and TBIPTPA luminophores were prepared by a condensation reaction between different aldehyde substrates, benzil, and aniline in the presence of ammonium acetate and acetic acid. The synthesis strategy of the targeted luminophores is shown in Scheme 1. The obtained luminophores were systematically characterized by nuclear magnetic resonance (NMR), elemental analysis, mass spectrometry, and Fourier-transform infrared (FTIR) spectroscopy.

\section{General synthesis procedure for the targeted fluorophores}

The mixture of TPA-CHO ( $0.5 \mathrm{~g}, 1$ eq.), benzil ( $0.42 \mathrm{~g}, 1.1$ eq.), aniline $(0.12 \mathrm{~g}, 1.3 \mathrm{eq}$.$) and acetic acid (25 \mathrm{~mL})$ was taken in a two-necked $50 \mathrm{~mL}$ round bottom flask. Into this, ammonium acetate $(1.40 \mathrm{~g}, 10 \mathrm{eq}$.) was added and stirred for 12 hours at $110{ }^{\circ} \mathrm{C}$. The reaction progress was monitored by TLC. After the completion of the reaction, the reaction mixture was allowed to cool at room temperature and poured into a minimum amount of distilled water; to this solution, dilute $\mathrm{NaOH}$ solution was added. The obtained solid was filtered with DCM and the solvent was evaporated. The obtained crude compound (BIPTPA) was purified with column chromatography using (100-200 mesh) silica and methanol in DCM (1:9) as the eluent. The synthesis procedures for DBIPTPA and TBIPTPA were the same as that mentioned above, but we had to increase the equivalence of the substrate accordingly.

$N$-Phenyl- $N$-(4-(1,4,5-triphenyl-1H-imidazol-2-yl)phenyl)benzenamine (BIPTPA). Yield: $71 \% .{ }^{1} \mathrm{H}-\mathrm{NMR}\left(400 \mathrm{MHz}, \mathrm{CDCl}_{3}\right.$, TMS, $\delta$ ppm): $7.58(\mathrm{~d}, 2 \mathrm{H}), 7.2-7.18(\mathrm{~m}, 15 \mathrm{H}), 7.12-7.10(\mathrm{~m}, 2 \mathrm{H})$, 7.07-7.0 (m, 8H), 6.89 (d, 2H). ${ }^{13} \mathrm{C}-\mathrm{NMR}\left(100 \mathrm{MHz}, \mathrm{CDCl}_{3}\right.$, TMS, $\delta$ ppm): 147.79, 147.31, 131.13, 129.62, 129.27, 129.05, 128.51, $128.31,128.26,128.13,127.87,127.39,126.54,124.85,123.26$, 122.14, 117.96, and 113.14. IR (KBr, v/ $\left.\mathrm{cm}^{-1}\right): 3043,1599,1491$, 1283, 1077, 1017, 957, 840, 756, 696. CHNS Elemental analysis: anal. calc. for $\mathrm{C}_{39} \mathrm{H}_{29} \mathrm{~N}_{3}$ : C, 86.80; H, 5.42; N, 7.79; Found: C, 87.08; H, 5.67; N, 8.15\%. EI-MS: $m / z=540.66[\mathrm{M}+\mathrm{H}]^{+}$.

$N$-Phenyl-4-(1,4,5-triphenyl-1H-imidazol-2-yl)- $N$-(4-(1,4,5-triphenyl$1 H$-imidazol-2-yl)phenyl)benzenamine (DBIPTPA). Yield: $67 \%$. ${ }^{1} \mathrm{H}-\mathrm{NMR}$ (400 MHz, $\mathrm{CDCl}_{3}$, TMS, $\delta$ ppm): $7.58(\mathrm{~d}, 4 \mathrm{H}), 7.27-7.16$ $(\mathrm{m}, 24 \mathrm{H}), \quad 7.12-7.01(\mathrm{~m}, 12 \mathrm{H}), 6.89(\mathrm{dd}, 4 \mathrm{H}) .{ }^{13} \mathrm{C}-\mathrm{NMR}$ (100 $\left.\mathrm{MHz}, \mathrm{CDCl}_{3}, \mathrm{TMS}, \delta \mathrm{ppm}\right): 147.79,131.13,129.62$, 129.27, 129.05, 128.51, 128.31, 128.26, 128.13, 127.87, 127.39, 126.54, 124.85, 123.26, 122.14, 117.04, 114.04, and 112.03. IR $\left(\mathrm{KBr}, \mathrm{v} / \mathrm{cm}^{-1}\right): 3046,1604,1481,1441,1281,1071,1021,961$, 842, 762, 701. CHNS Elemental analysis: anal. calc. for $\mathrm{C}_{60} \mathrm{H}_{43} \mathrm{~N}_{5}$ : C, 86.41; H, 5.20; N, 8.40; Found: C, 86.78; H, 5.61; N, $8.65 \%$. EI-MS: $m / z=834.86[\mathrm{M}+\mathrm{H}]^{+}$.

Tris(4-(1,4,5-triphenyl-1H-imidazol-2-yl)phenyl)amine (TBIPTPA). Yield: $60 \% .{ }^{1} \mathrm{H}-\mathrm{NMR}\left(400 \mathrm{MHz}, \mathrm{CDCl}_{3}\right.$, TMS, $\left.\delta \mathrm{ppm}\right): 7.58(\mathrm{~d}, 6 \mathrm{H})$, 7.29-7.18 (m, 30H), 7.12-7.04 (m, 15H), $6.87(\mathrm{~d}, 6 \mathrm{H}) .{ }^{13} \mathrm{C}-\mathrm{NMR}$ (100 MHz, $\mathrm{CDCl}_{3}$, TMS, $\delta$ ppm): 147.07, 137.97, 131.06, 130.38, $129.10,128.96,128.42,128.35,128.21,127.93,127.52,126.68$, $125.69,124.30,120.40,120.02,118.86$, and 114.04. IR (KBr, $\left.\mathrm{v} / \mathrm{cm}^{-1}\right): 3059,1600,1490,1440,1370,1290,1180,1031,961$, 841, 771, 691. CHNS Elemental analysis: anal. calc. for $\mathrm{C}_{81} \mathrm{H}_{57} \mathrm{~N}_{7}$ : C, 86.22; H, 5.09; N, 8.69; found: C, 86.41; H, 5.37; N, $8.87 \%$. EI-MS: $m / z=1128.83[\mathrm{M}+\mathrm{H}]^{+}$.

\section{Thermal properties}

The thermal properties of the BIPTPA, DBIPTPA, and TBIPTPA luminophores were studied by thermogravimetric analysis (TGA) with the scan rate of $10{ }^{\circ} \mathrm{C} \mathrm{min}^{-1}$ under an $\mathrm{N}_{2}$ atmosphere; the related graphs are shown in Fig. 1. The synthesized luminophores reflected good thermal stability and had a high decomposition temperature $\left(T_{\mathrm{d}}\right)$. The $T_{\mathrm{d}}$ values corresponding to $5 \%$ weight loss were found to be 321,385 and $418{ }^{\circ} \mathrm{C}$ for BIPTPA, DBIPTPA, and TBIPTPA, respectively (Table 1). Among all the luminophores, the TBIPTPA luminophore showed the highest $T_{\mathrm{d}}$ of $418{ }^{\circ} \mathrm{C}$ related to $5 \%$ weight loss compared with 

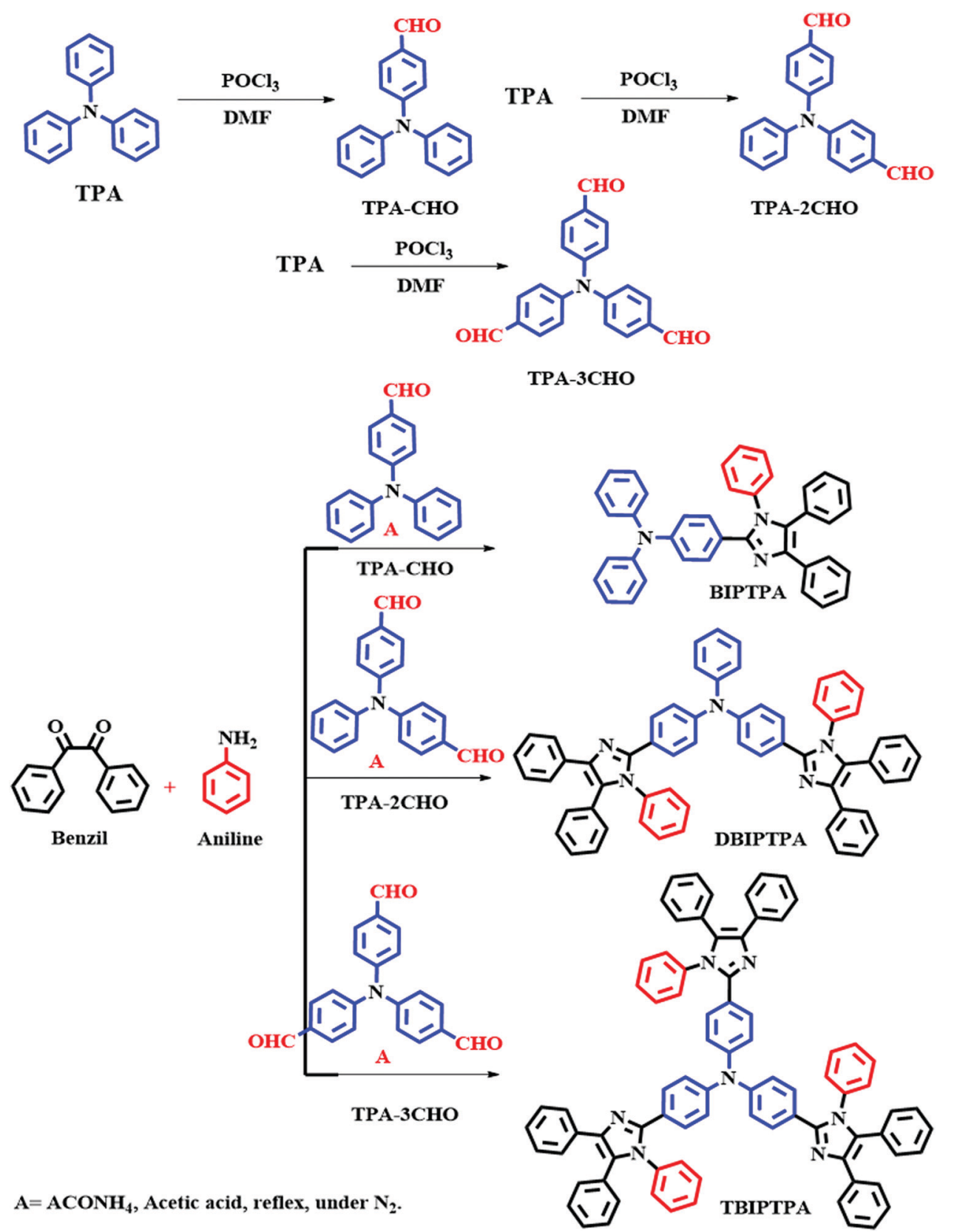

Scheme 1 Synthetic scheme of triphenylamine-imidazole derivatives.

the other luminophores (BIPTPA and DBIPTPA) due to the increased molecular mass with the addition of two diphenylimidazole moieties. The thermal stability of triphenylamine derivatives has been well-established in the literature. ${ }^{19}$

\section{Photophysical properties}

The absorption spectra of the luminophores were measured in a dichloromethane (DCM) solution $\left(10^{-5} \mathrm{~mol} \mathrm{~L}^{-1}\right)$; the obtained absorption spectra are shown in Fig. 2a and the corresponding data are listed in Table 1. All the luminophores exhibited two noticeable absorption peaks between 240 and $400 \mathrm{~nm}$. The absorption peaks at about $270 \mathrm{~nm}$ for all the luminophores are because of the $\pi-\pi^{*}$ transition in the benzene ring ${ }^{20}$ and the weak absorption bands at around $370 \mathrm{~nm}$ are attributed to the intramolecular charge transfer (ICT) interaction from the electron-donating group to the electron-withdrawing functional group. ${ }^{21}$ The calculated UV absorption spectrum (by DFT) is shown in Fig. 2d, and the obtained absorption wavelengths are supported by the experimental findings. The absorption spectra of the luminophores in the solid state were broad and redshifted as compared with that in solutions $(\sim 290$ and $\sim 380 \mathrm{~nm})$ (Fig. 2b); the red-shift was because of the strong $\pi-\pi^{*}$ molecular interactions. ${ }^{22}$ The graphs of molar extinction coefficient $(\varepsilon) v s$. wavelength for the prepared luminophores in solution and solid 


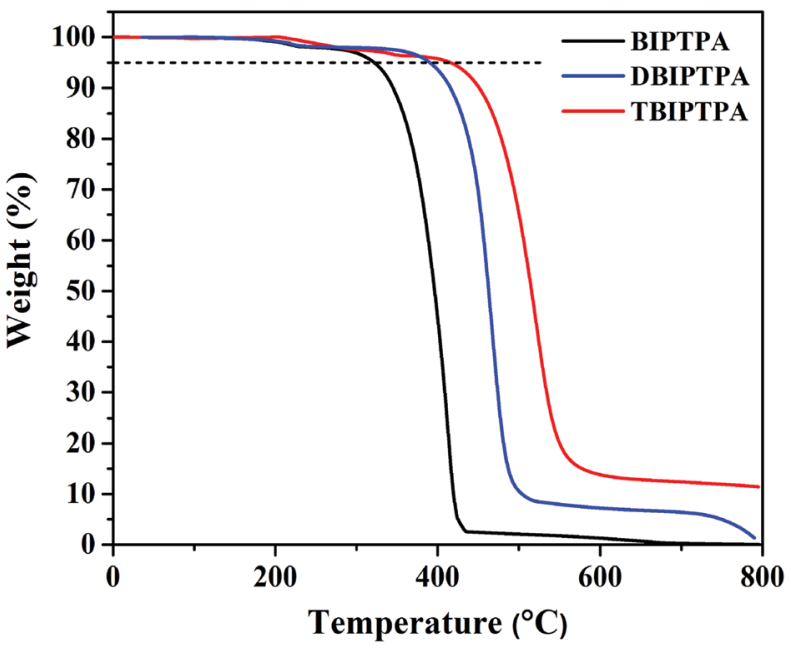

Fig. 1 Thermogravimetric curves of the luminophores.

states are presented in Fig. S11 and the corresponding data are given in Table S2 in the ESI. $\dagger$ The DBIPTPA and TBIPTPA luminophores showed higher molar extinction coefficient values than the BIPTPA luminophore due to the increase in the $\pi$-conjugated functional groups (diphenylimidazole groups). The obtained molar extinction coefficient data indicated that the incorporation of the diphenylimidazole group in the triphenylamine group certainly changed the structural properties of the luminophores. ${ }^{23}$ From the solid-state absorption spectra (Fig. 2c), we obtained the optical bandgap of the luminophores, which was calculated with the help of the Kubelka-Munk function $;^{24}$ the obtained optical bandgaps were $2.68 \mathrm{eV}$ (BIPTPA), $2.61 \mathrm{eV}$ (DBIPTPA) and $2.41 \mathrm{eV}$ (TBIPTPA).

The peaks in the PL emission spectra of BIPTPA, DBIPTPA, and TBIPTPA in DCM solutions were observed at 445, 450, and $471 \mathrm{~nm}$, respectively (Fig. 2a). The red-shift of $26 \mathrm{~nm}$ for TBIPTPA was primarily due to the increase in $\pi$-conjugation. This indicates that the combination of an electron acceptor and an electron donor will further boost the $\pi$-electron delocalization upon excitation. ${ }^{25}$ Meanwhile, the molar extinction coefficient increased on increasing the $\pi$-conjugation of the luminophores. The PL emission spectra of the DBIPTPA and TBIPTPA luminophores in the solid state red-shifted (Fig. 2b) and the observed redshifts could be interpreted by their relatively stronger $\pi-\pi$ molecular interactions. ${ }^{26}$

The CIE chromaticity diagrams of the prepared luminophores in solution and solid states are displayed in Fig. 3, indicating the change in PL emission on increasing the $\pi$-conjugation.
By using an integrating sphere for both the solution and solid phases, the absolute quantum yield of the luminophores was calculated. The absolute quantum yield $(\Phi)$ (integration sphere) of the luminophores was obtained by using the following eqn (1): ${ }^{27}$

$$
\begin{gathered}
\Phi=\frac{L_{0}(\lambda)-L_{i}(\lambda)}{L_{0}(\lambda)} \\
\eta=\frac{E_{i}(\lambda)-(1-\Phi) E_{0}(\lambda)}{E_{0}(\lambda) \Phi}
\end{gathered}
$$

The calculated QYs of the luminophores BIPTPA, DBIPTPA, and TBIPTPA in solutions were $14.5,38.3$ and $25.6 \%$, respectively. In the case of solid luminophores, the QY values were 11.3, 21.2 and $13.5 \%$ for BIPTPA, DBIPTPA, and TBIPTPA, respectively. The difference in the QYs might result from exciton migration due to the variation in the sizes of the luminophores. $^{28}$ The measured QY values are shown in Table 1 and the measured QY digital images can be seen in Section SI 5 in the ESI. $\dagger$

\section{Theoretical calculations}

Density functional theory (DFT) calculations were performed to obtain information about the electronic structures of the synthesized luminophores using the B3LYP/6-31G(d,p) basis set. ${ }^{29}$ The optimized geometries and frontier molecular orbitals of the luminophores are displayed in Fig. 4 and 5, respectively. The HOMOs of BIPTPA, DBIPTPA, and TBIPTPA were mostly populated on the triphenylamine moiety, while the LUMOs were located on the diphenylimidazole moiety and phenyl linkage. This indicated a considerable charge transfer from amine (donor) to diphenylimidazole (acceptor), resulting in absorption in the visible wavelength region. The calculated HOMO/LUMO values of the luminophores were $-4.76 /$ $-0.77 \mathrm{eV}$ (BIPTPA), $-4.68 /-0.90 \mathrm{eV}$ (DBIPTPA), and $-4.62 /$ $-0.95 \mathrm{eV}$ (TBIPTPA). The predicted HOMO-LUMO energy differences of $3.99 \mathrm{eV}$ (BIPTPA), $3.78 \mathrm{eV}$ (DBIPTPA) and $3.67 \mathrm{eV}$ (TBIPTPA) were in very good agreement with the experimental results (Table 3). The HOMO-LUMO energy gap of TBIPTPA was less than that of BIPTPA and DBIPTPA, which suggested that there could be redshifts due to the extension of conjugation on the replacement of the hydrogen atom (from TPA) with the diphenylimidazole moieties. Using the TD-DFT analysis, singlet and triplet energy levels were calculated and displayed in Table 2. The calculated excitation wavelengths, their oscillatory strength $(f)$ and orbital

\begin{tabular}{|c|c|c|c|c|c|c|c|c|}
\hline Luminophores & $T_{\mathrm{d}}{ }^{a}\left({ }^{\circ} \mathrm{C}\right)$ & \multicolumn{2}{|l|}{ Solution } & \multicolumn{2}{|l|}{ Solid } & \multicolumn{2}{|c|}{ Absolute quantum yield } & $\lambda_{\text {abs }}{ }^{b}(\mathrm{~nm})$ (calculated) $(f)$ \\
\hline BIPTPA & 321 & 276,360 & 445 & 290,381 & 446 & 11.3 & 14.5 & $353(0.819)$ \\
\hline ТВIPTPA & 418 & 273,370 & 471 & 290,382 & 580 & 13.5 & 25.6 & $386(0.804)$ \\
\hline
\end{tabular}

Table 1 Key photophysical properties of BIPTPA, DBIPTPA, and TBIPTPA

${ }^{a}$ Thermal decomposition temperature related to $5 \% .{ }^{b}$ Calculated at B3LYP/6-31G(d,p) basis set in the gas phase, $f=$ oscillator strength. 

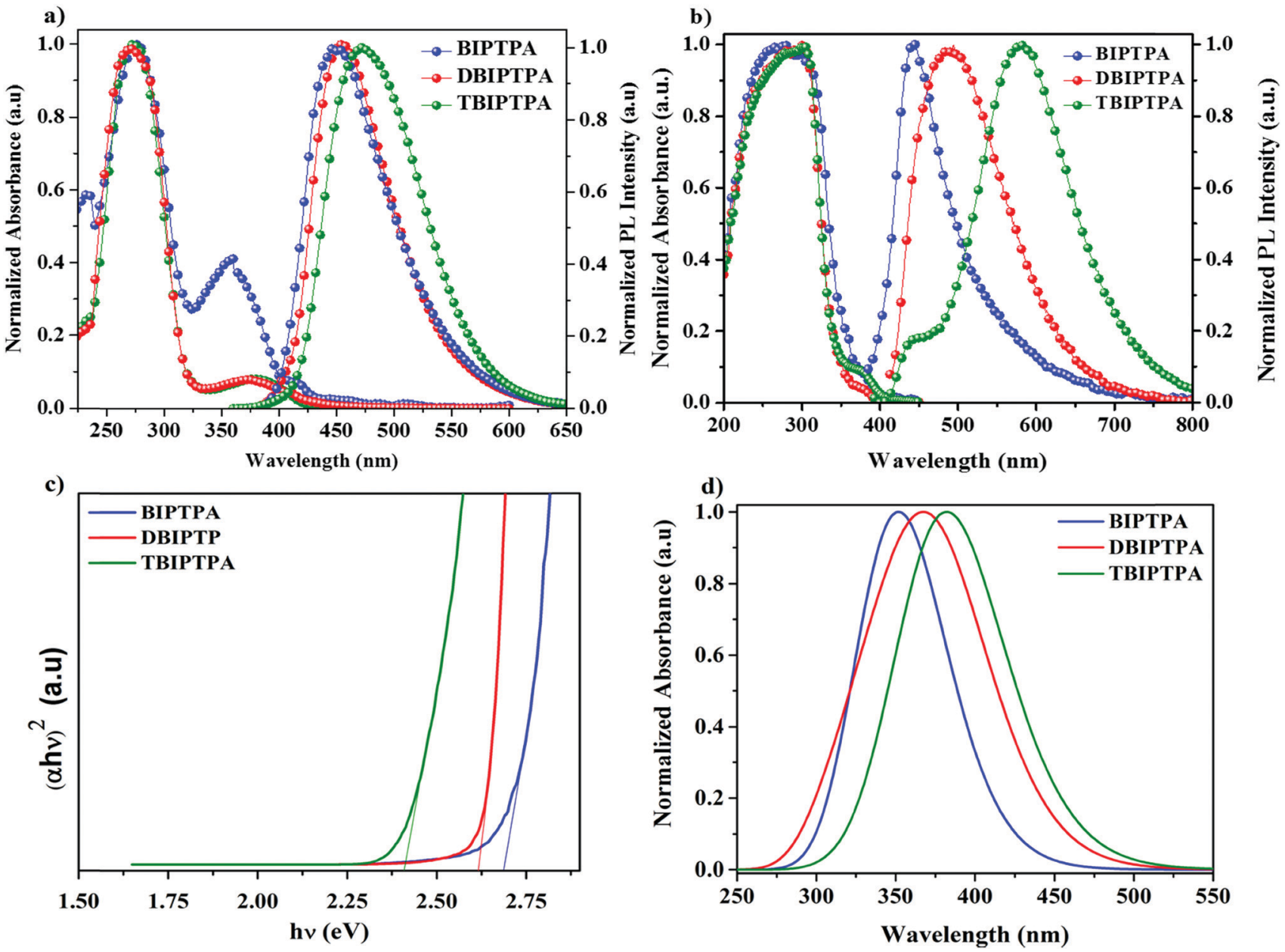

Fig. 2 UV absorption and PL spectra of luminophores in the DCM solution (a) and solid state (b); solid-state diffuse reflectance spectra (c) and calculated (DFT) UV absorption spectra (d).

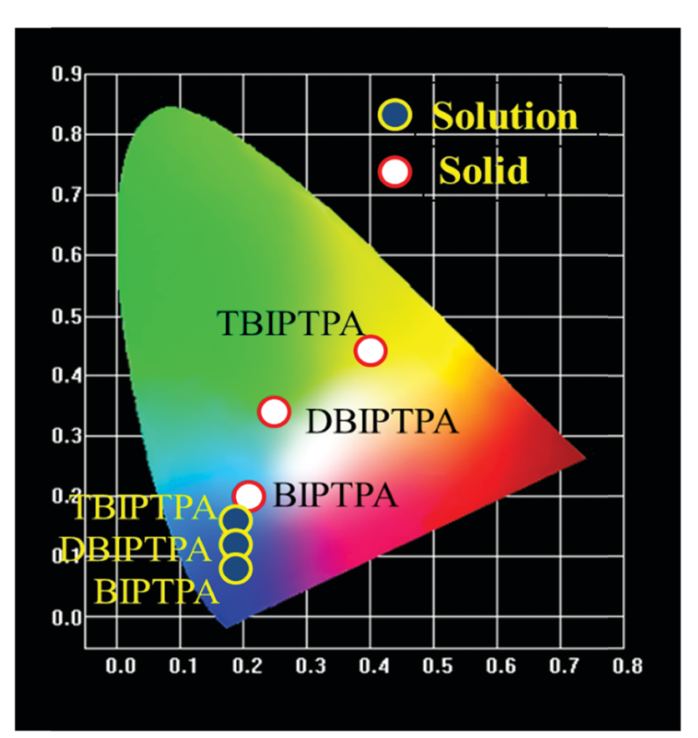

Fig. 3 The CIE chromaticity diagram of luminophores in solutions and solid phase.

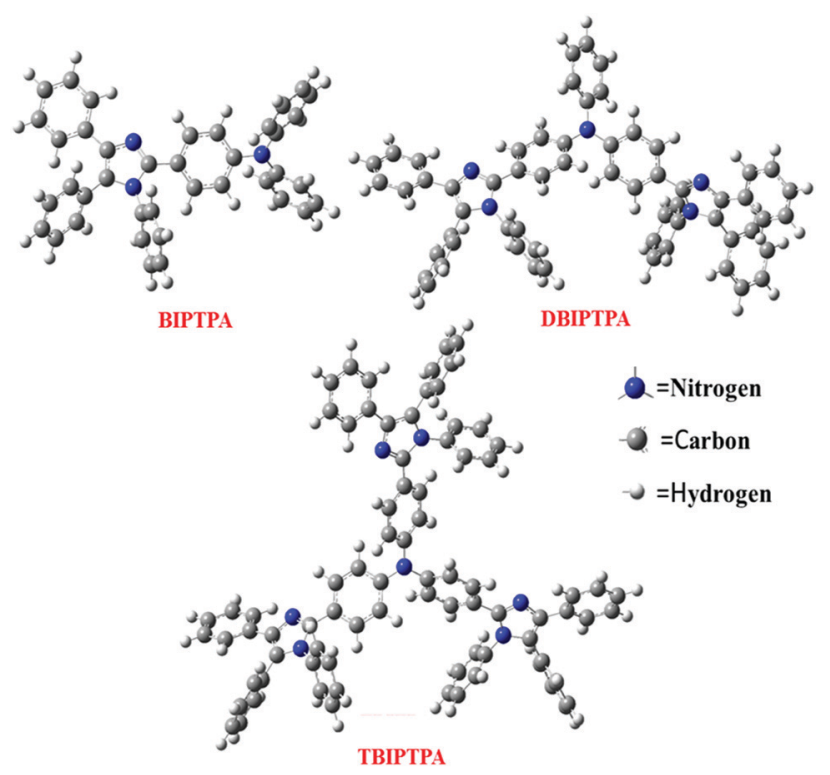

Fig. 4 Optimized structures of BIPTPA, DBIPTPA, and TBIPTPA luminophores. 


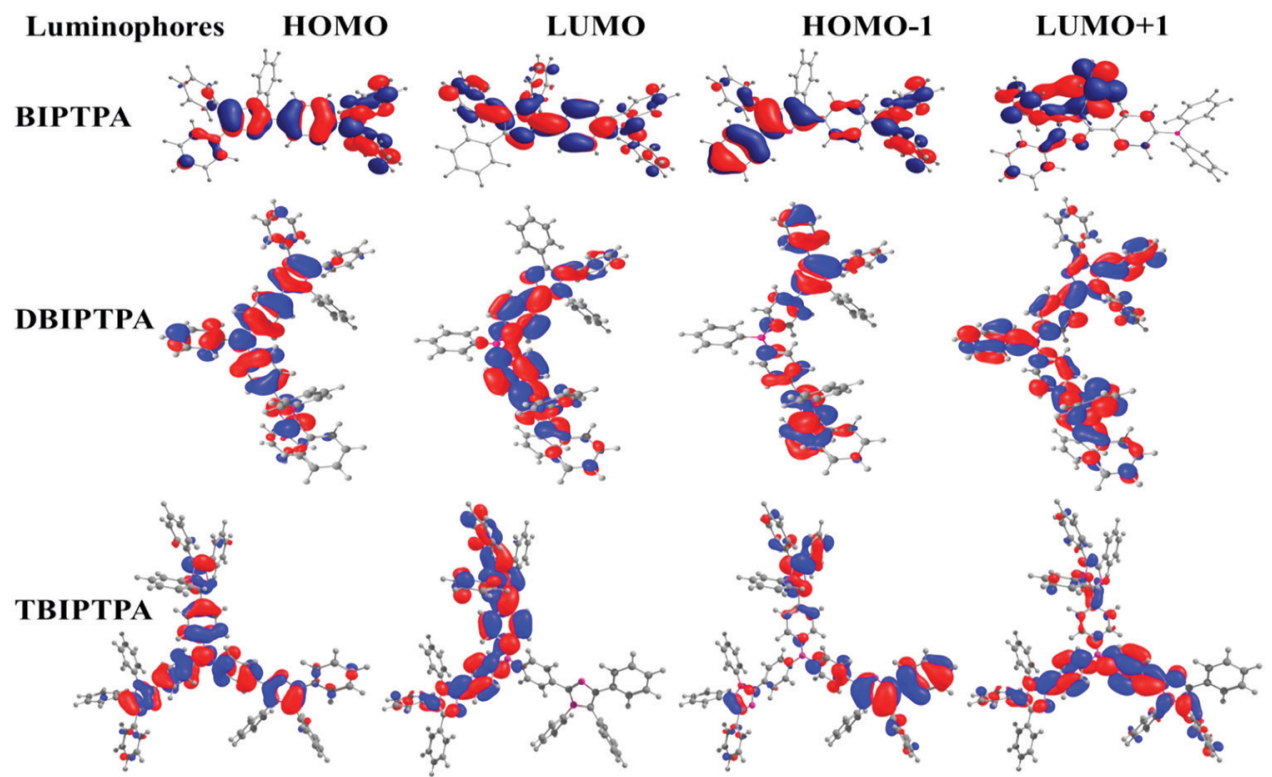

Fig. 5 Electron density outlines of the frontier molecular orbitals (FMOs) of the luminophores.

Table 2 Frontier molecular orbital energy values calculated from DFT

\begin{tabular}{llllllll}
\hline Luminophores & HOMO $(\mathrm{eV})$ & LUMO $(\mathrm{eV})$ & HOMO-1 $(\mathrm{eV})$ & LUMO+1 $(\mathrm{eV})$ & $E_{\mathrm{g}}(\mathrm{eV})$ & $S 1(\mathrm{gas})(\mathrm{eV})$ & $T 1(\mathrm{gas})(\mathrm{eV})$ \\
\hline BIPTPA & -4.76 & -0.77 & -5.41 & -0.606 & 3.99 & 3.51 & 2.69 \\
DBIPTPA & -4.68 & -0.90 & -5.21 & -0.68 & 3.78 & 3.27 & 2.60 \\
TBIPTPA & -4.62 & -0.95 & -5.19 & -0.89 & 3.67 & 3.21 & 2.59
\end{tabular}

contribution of the luminophores can be seen in Table S4 (ESI $\dagger)$. Also, the atom coordinates of the luminophores are provided in $\mathrm{ESI} \dagger$ (SI 6).

\section{Electrochemical properties}

The electrochemical properties of the newly synthesized fluorophores were determined by cyclic voltammetry (CV) in DMF solutions with a scanning rate of $100 \mathrm{mV} \mathrm{s}^{-1}$ by using $0.1 \mathrm{M}$ tetrabutylammonium perchlorate $\left(\mathrm{Bu}_{4} \mathrm{NClO}_{4}\right)$ as the supporting electrolyte. The cyclic voltammograms are displayed in Fig. 6 and the corresponding electrochemical data are provided in Table 3 . The different oxidation and reduction behaviours of all the luminophores can be seen in Fig. 6, indicating their potential bipolar carrier transporting nature. We calculated the HOMO and LUMO energy levels from the onset potential values using eqn (2) and (3), respectively, reported by de Leeuw et $a .^{30}$

$$
\begin{aligned}
& E_{\text {HOMO }}=-\left(E_{\text {ox }}^{\text {onset }}+4.4\right) \mathrm{eV} \\
& E_{\text {LUMO }}=-\left(E_{\text {red }}^{\text {onset }}+4.4\right) \mathrm{eV}
\end{aligned}
$$

The HOMO/LUMO energy levels of the luminophores were $-5.59 /-3.12 \mathrm{eV}$ (BIPTPA), -5.58/-3.13 eV (DBIPTPA), and $-5.54 /-3.22 \mathrm{eV}$ (TBIPTPA), with the energy band gaps of $2.47 \mathrm{eV}$ (BIPTPA), $2.45 \mathrm{eV}$ (DBIPTPA) and $2.32 \mathrm{eV}$ (TBIPTPA). The comparison of the HOMO-LUMO energy band gaps of all the luminophores is displayed in Fig. 7, indicating that the

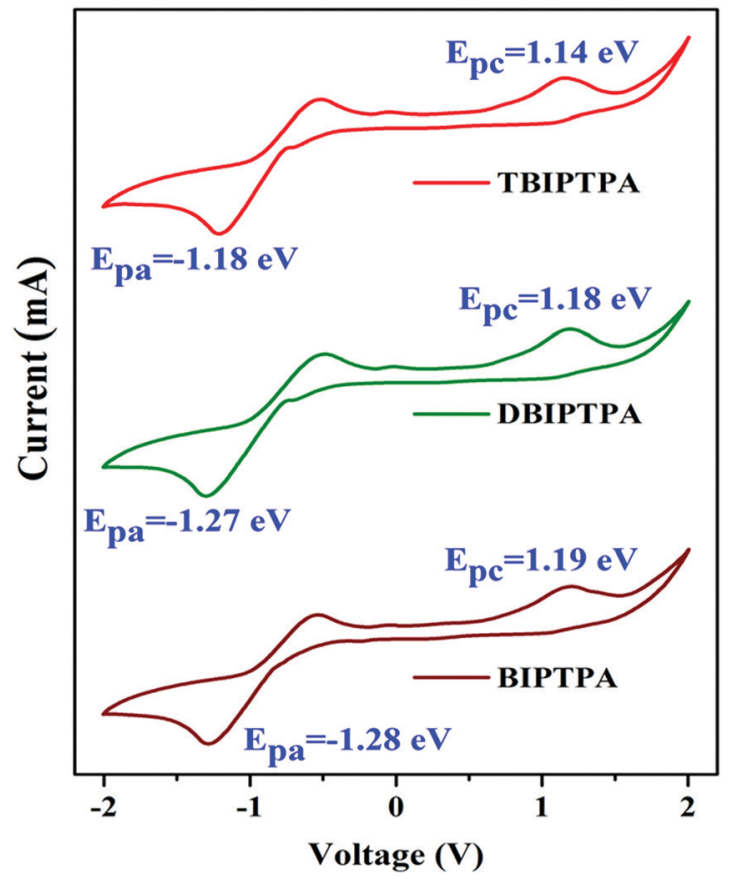

Fig. 6 Cyclic voltammograms of BIPTPA, DBIPTPA and TBIPTPA luminophores.

band gaps obtained using both optical and electrochemical analyses are in good agreement. 
Table 3 Electrochemical properties of BIPTPA, DBIPTPA, and TBIPTPA luminophores

\begin{tabular}{llllllll}
\hline Luminophores & $\begin{array}{l}E_{\mathrm{ox}}{ }^{a} \\
(\mathrm{~V})\end{array}$ & $\begin{array}{l}E_{\mathrm{red}}{ }^{b} \\
(\mathrm{~V})\end{array}$ & $\begin{array}{l}\text { HOMO } \\
(\mathrm{eV})\end{array}$ & $\begin{array}{l}\text { LUMO } \\
(\mathrm{eV})\end{array}$ & $\begin{array}{l}E_{\mathrm{g}}{ }^{c} \\
(\mathrm{eV})\end{array}$ & $\begin{array}{l}E_{\mathrm{g}}{ }^{d} \\
(\mathrm{eV})\end{array}$ & $\begin{array}{l}E_{\mathrm{g}}{ }^{2} \\
(\mathrm{eV})\end{array}$ \\
\hline BIPTPA & 1.19 & -1.28 & -5.59 & -3.12 & 2.47 & 2.68 & 3.99 \\
DBIPTPA & 1.18 & -1.27 & -5.58 & -3.13 & 2.45 & 2.61 & 3.78 \\
TBIPTPA & 1.14 & -1.18 & -5.54 & -3.22 & 2.32 & 2.41 & 3.67
\end{tabular}

${ }^{a}$ Onset oxidation potential. ${ }^{b}$ Onset reduction potential. ${ }^{c}$ Electrochemical band gap. ${ }^{d}$ Optical energy band gap. ${ }^{e}$ Theoretical band gap.

\section{Electroluminescence characteristics}

To evaluate the electroluminescence (EL) characteristics of the newly synthesized luminophore molecules (BIPTPA, DBIPTPA, and TBIPTPA), mainly, two types of multi-layer OLED devices, i.e., undoped and doped were fabricated through a simple solution-process technique. The synthesized organic luminophores were used as a pure dopant (100 wt\%) or doped in the CBP host with different concentrations (1, 3 and $5 \mathrm{wt} \%)$. The OLED device configuration was ITO (125 nm)/PEDOT:PSS $(35 \mathrm{~nm}) /$ emitter $(22 \mathrm{~nm}) / \mathrm{TPBi}(40 \mathrm{~nm}) / \mathrm{LiF}(1 \mathrm{~nm}) / \mathrm{Al}(100 \mathrm{~nm})$ for the undoped devices and ITO (125 nm)/PEDOT:PSS (35 nm)/ CBP:emitter $(22 \mathrm{~nm}) / \mathrm{TPBi}(40 \mathrm{~nm}) / \mathrm{LiF}(1 \mathrm{~nm}) / \mathrm{Al}(100 \mathrm{~nm})$ for the doped devices. Among them, poly(3,4-ethylenedioxythio-phene)poly-(styrenesulfonate) (PEDOT:PSS), 1,3,5-tris( $N$-phenylbenzimidazol-2-yl)benzene (TPBi), lithium fluoride (LiF), and aluminum (Al) were successfully employed as a hole-injection layer (HIL), electron-transporting or hole-blocking layer (ETL/ $\mathrm{HBL}$ ), electron injection layer (EIL), and cathode, respectively. For the doped devices, CBP was employed as the host because it
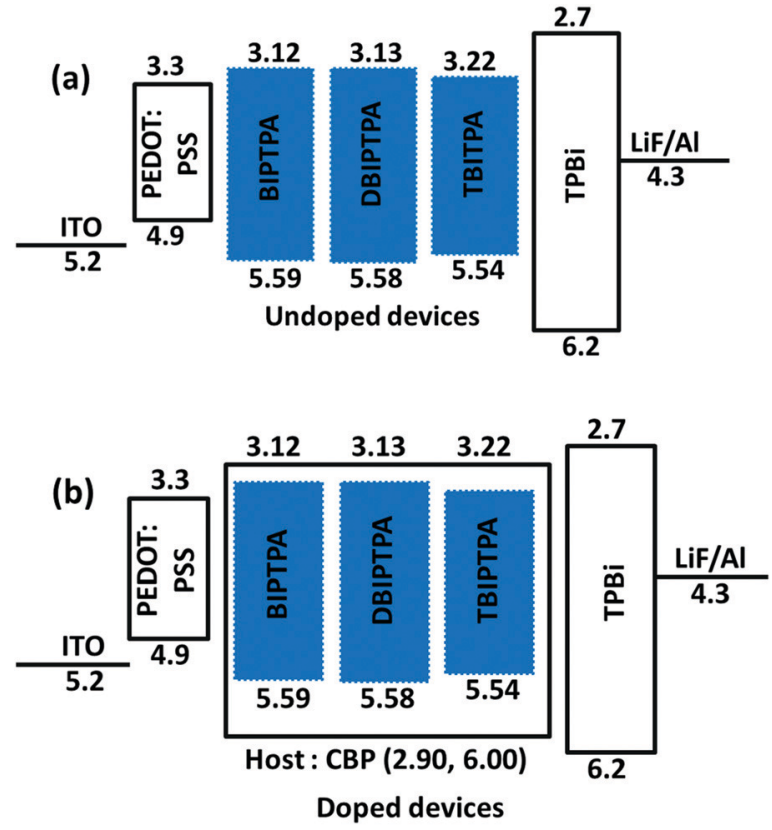

Fig. 8 Schematic representation of the energy levels of the solutionprocessed OLEDs composed of deep-blue BIPTPA, DBIPTPA and TBIPTPA emitters (a) undoped and (b) doped in CBP host devices.

possesses suitable occupied and unoccupied molecular orbital energy levels and bipolar nature to ensure effectual charge trapping performed by the luminophore emitters. The schematic energy level orientation of the materials used in the OLED devices is depicted in Fig. 8. It is evident that the injection of

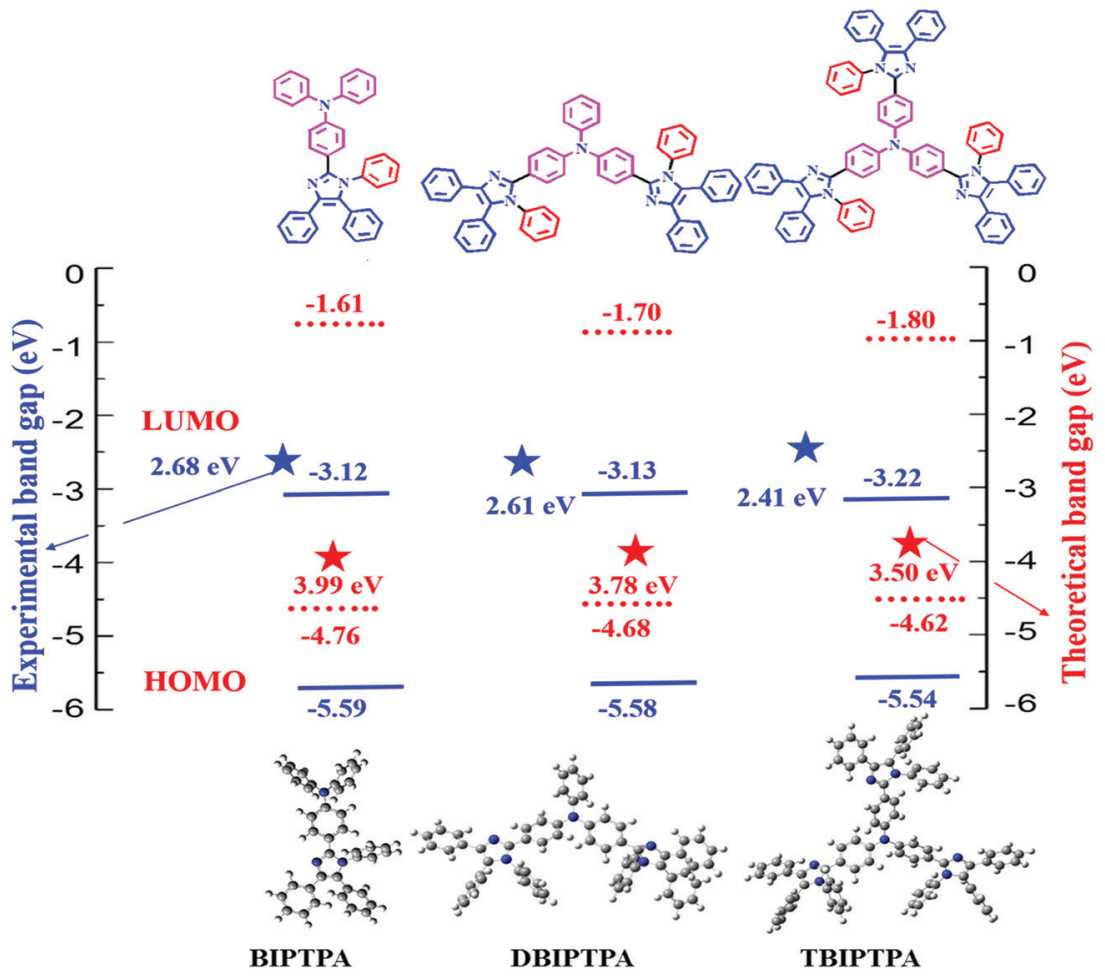

Fig. 7 HOMO-LUMO energy gap diagram of BIPTPA, DBIPTPA, and TBIPTPA luminophores. 

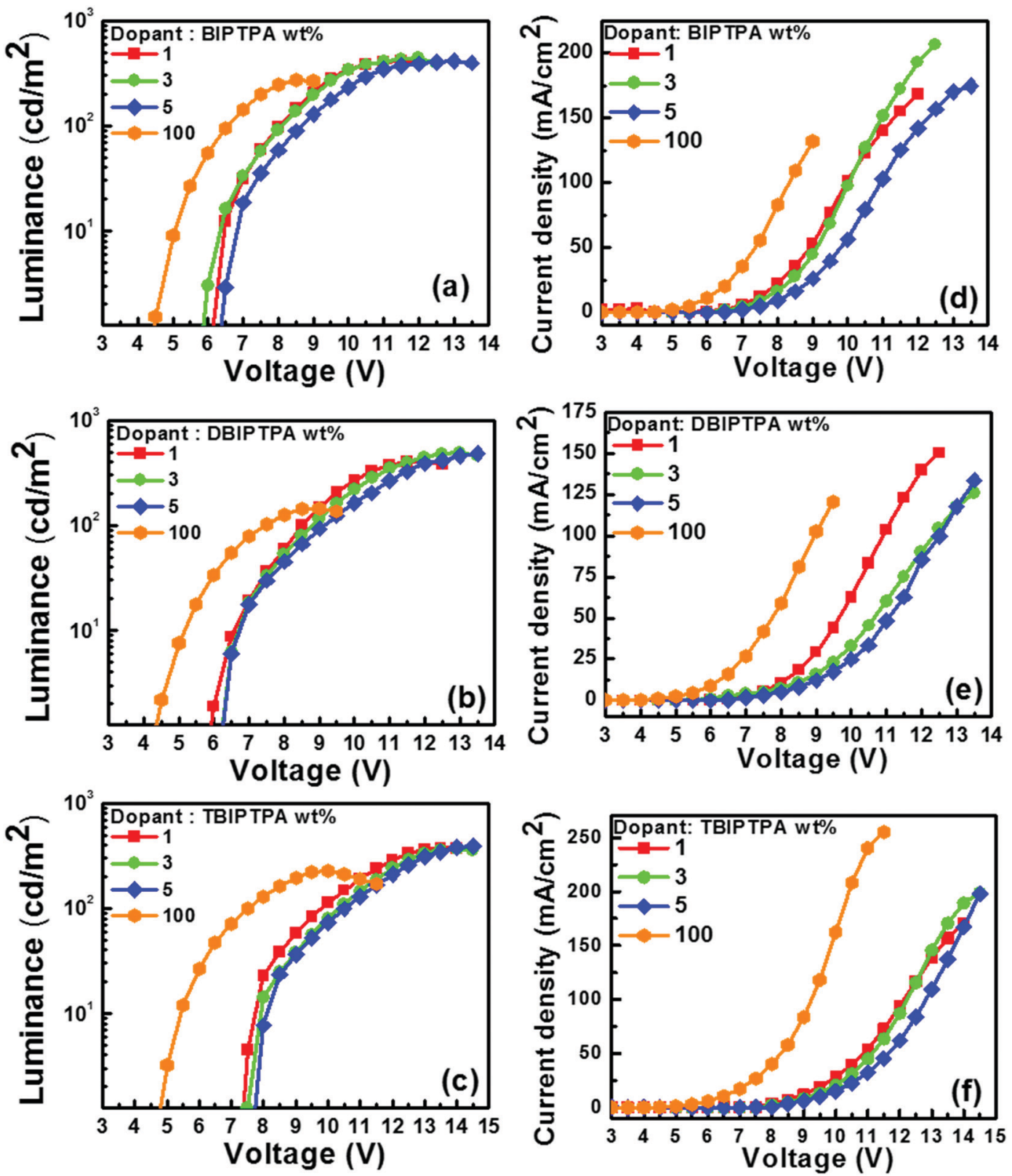

Fig. 9 Luminance-current density $(a-c)$ and current density-voltage ( $d-f)$ plots of the solution-processed OLED devices with BIPTPA, DBIPTPA and TBIPTPA dopants at various concentrations in the CBP host.

holes and electrons across the emitting layer is facile and does not entail the restricting energy barrier.

The luminescence-voltage and current density-voltage characteristics of all the fabricated undoped and doped devices are shown in Fig. 9-11 and the pertinent electroluminescence characteristics are summarized in Table 4. It was interesting to note that all the fabricated undoped OLED devices displayed high current density but low brightness at the same applied voltage, which might be attributed to the charge carrier leakage at the material/electrode interface. The observed poor efficiency of the undoped devices is attributed to the large hole-injection barrier $(\leq 0.64 \mathrm{eV})$ between PEDOT:PSS and the emissive layer as compared to the electron-injection barrier $(\leq 0.18 \mathrm{eV})$ between the emissive layer and TPBi, which can hamper the charge balance across the molecular layers.

In order to improve the electroluminescence performance of the synthesized luminophores, a high triplet energy bipolar host matrix CBP was employed and the doping concentration was optimized from $1 \mathrm{wt} \%$ to $5 \mathrm{wt} \%$. All the doped devices displayed reduced current density, increased maximum brightness and improved efficacy, which may be due to the (i) balanced charge carrier in the recombination zone, (ii) fine matching of the molecular orbital levels and triplet energy of the employed host material with the designed emitters, (iii) efficient host-toguest energy transfer, and (iv) feasibility of the generation of radiative excitons on both the host and the guest. A decrease in 
Table 4 Effects of doping concentrations of the synthesized deep-blue emitters BIPTPA, DBIPTPA and TBIPTPA with the molecular CBP host

\begin{tabular}{|c|c|c|c|c|c|c|c|c|}
\hline \multirow[b]{2}{*}{ Dopant } & \multirow[b]{2}{*}{ Device } & \multirow{2}{*}{$\begin{array}{l}\text { Dopant } \\
\text { conc. }[\mathrm{wt} \%]\end{array}$} & \multicolumn{5}{|c|}{ at $100 \mathrm{~cd} \mathrm{~m}^{-2}$} & \multirow{2}{*}{ 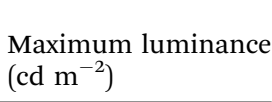 } \\
\hline & & & $\mathrm{OV}[\mathrm{V}]$ & $\mathrm{PE}\left[\operatorname{lm} \mathrm{W}^{-1}\right]$ & $\mathrm{CE}\left[\mathrm{cd} \mathrm{A}{ }^{-1}\right]$ & $\mathrm{EQE}[\%]$ & CIE $_{x, y}$ coordinates & \\
\hline \multirow[t]{4}{*}{ BIPTPA } & $\mathrm{I}-1$ & 100 & 6.6 & 0.2 & 0.5 & 0.4 & $(0.17,0.15)$ & 271 \\
\hline & $\mathrm{I}-2$ & 1 & 8.0 & 0.2 & 0.4 & 1.2 & $(0.17,0.06)$ & 416 \\
\hline & $\mathrm{I}-3$ & 3 & 8.1 & 0.2 & 0.5 & 1.6 & $(0.16,0.06)$ & 439 \\
\hline & $\mathrm{I}-4$ & 5 & 8.6 & 0.2 & 0.5 & 1.2 & $(0.16,0.07)$ & 413 \\
\hline \multirow[t]{4}{*}{ DBIPTPA } & II-1 & 100 & 7.4 & 0.1 & 0.3 & 0.2 & $(0.18,0.17)$ & 145 \\
\hline & II-2 & 1 & 8.5 & 0.2 & 0.5 & 1.6 & $(0.17,0.06)$ & 413 \\
\hline & II-3 & 3 & 8.8 & 0.3 & 0.7 & 2.5 & $(0.16,0.06)$ & 495 \\
\hline & II-4 & 5 & 9.0 & 0.3 & 0.8 & 2.0 & $(0.16,0.06)$ & 480 \\
\hline \multirow[t]{4}{*}{ TВIPTPA } & III-1 & 100 & 7.5 & 0.2 & 0.4 & 0.2 & $(0.33,0.38)$ & 228 \\
\hline & III-2 & 1 & 9.8 & 0.1 & 0.4 & 0.4 & $(0.20,0.19)$ & 379 \\
\hline & III-3 & 3 & 10.3 & 0.1 & 0.4 & 0.3 & $(0.21,0.20)$ & 371 \\
\hline & III-4 & 5 & 10.5 & 0.1 & 0.4 & 0.3 & $(0.21,0.21)$ & 394 \\
\hline
\end{tabular}
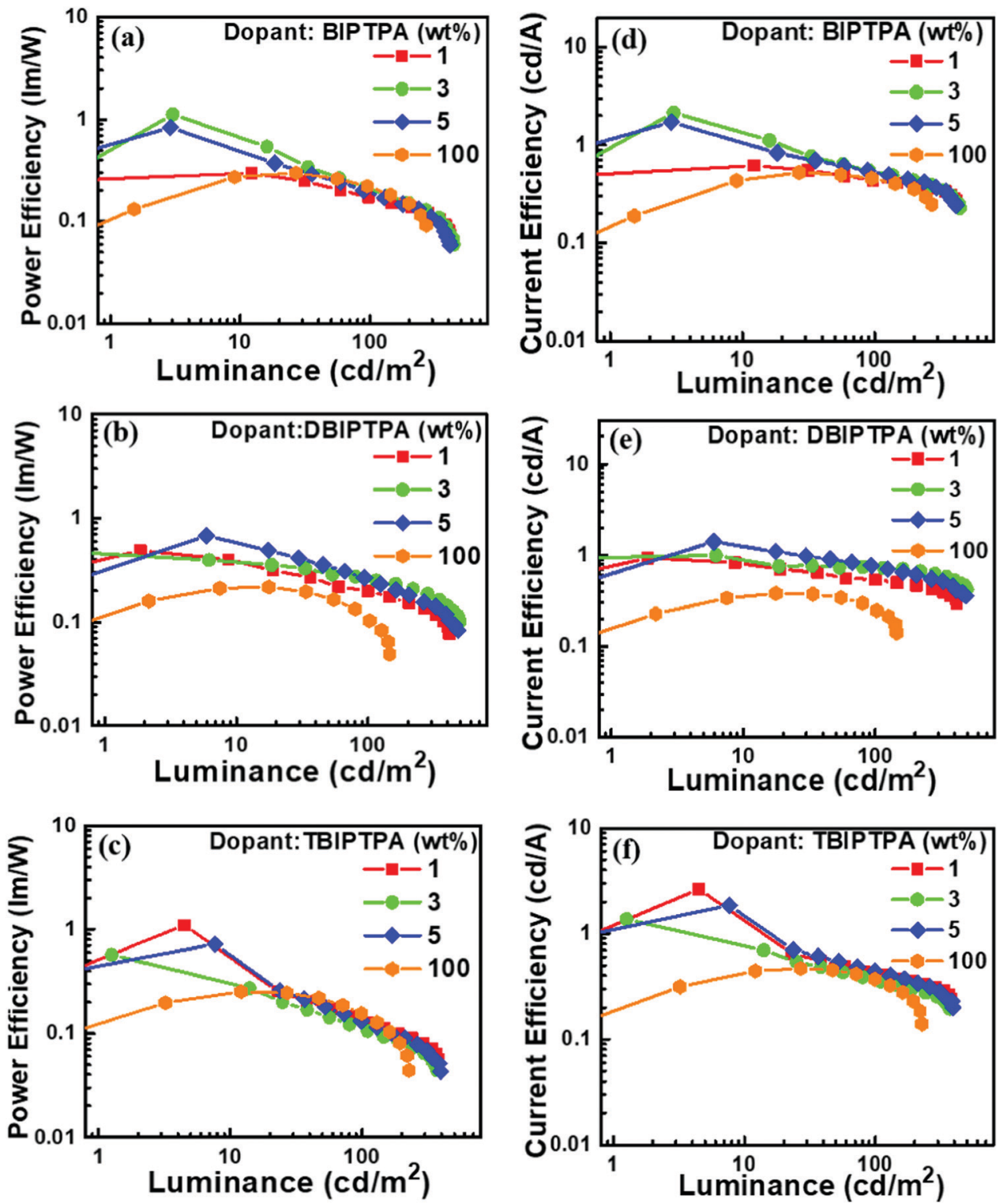

Fig. 10 Power efficiency-luminance $(a-c)$ and current efficiency-luminance $(d-f)$ plots of the solution-processed OLED devices with BIPTPA, DBIPTPA and TBIPTPA dopants at various concentrations in the CBP host. 

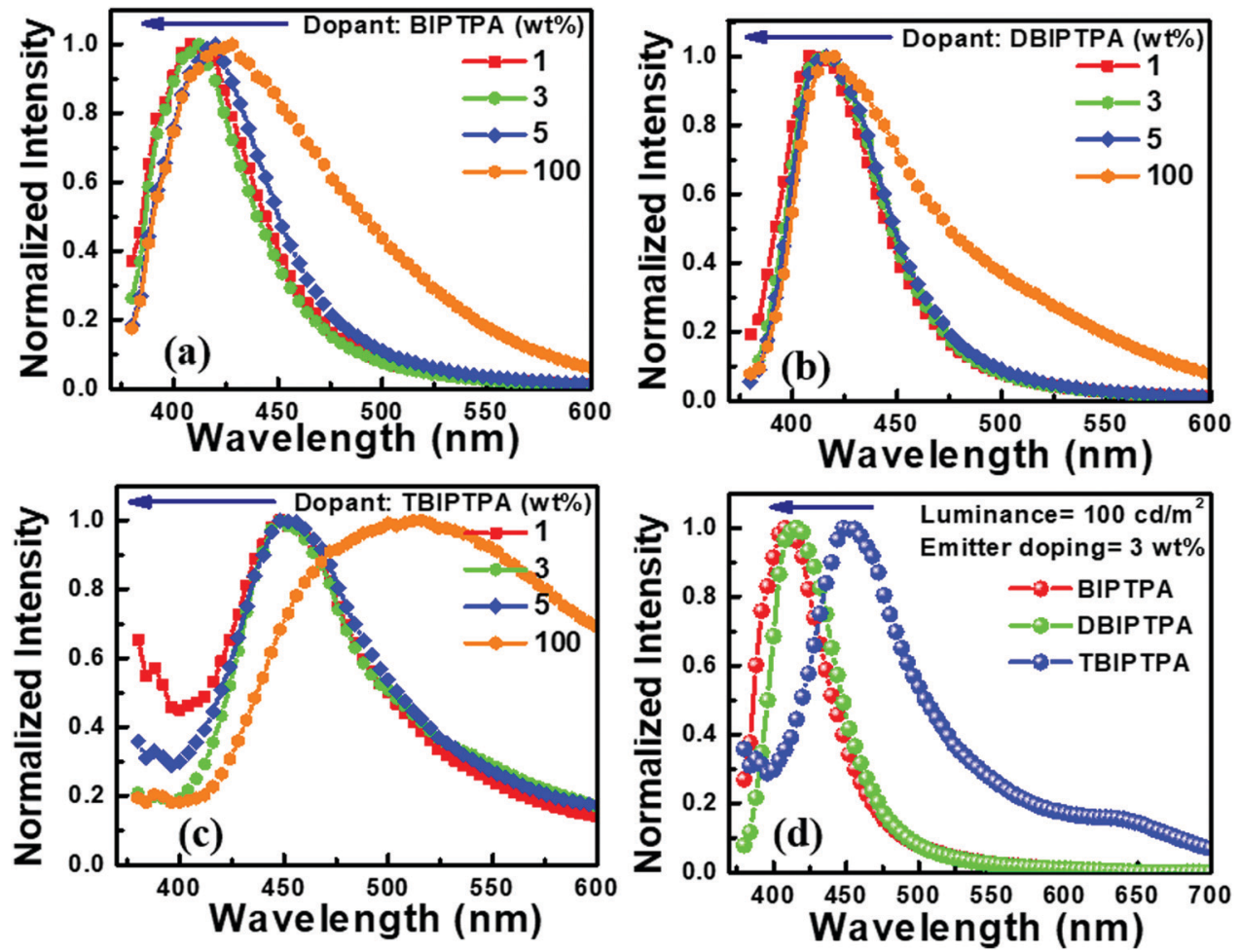

Fig. 11 (a-c) EL spectra of the solution-processed OLEDs by using BIPTPA, DBIPTPA and TBIPTPA dopants at different doping concentrations; (d) EL spectra of the devices containing $3 \mathrm{wt} \%$ dopants at a brightness of $100 \mathrm{~cd} \mathrm{~m}^{-2}$.

the brightness of OLED devices after a threshold voltage is characteristic of the formation of non-radiative excitons in the emissive layer, which may be quenched at the electrode without emission.

The doping concentration of emitters strongly influences the performance of OLED devices. For example, as the doping concentration of DBIPTPA increased from 3 to $5 \mathrm{wt} \%$, the external quantum efficiency (EQE) of the device drastically decreased from 2.5 to $2.0 \%$, respectively, which indicated a $20 \%$ decrement. Similar results were also observed for the other two emitters BIPTPA and TBIPTPA. Remarkably, all the fabricated OLED devices displayed maximum luminescence, current efficiency, power efficiency and EQE at $3 \mathrm{wt} \%$ doping concentration. This can be explained in terms of the substantial role of the balanced charge-carrier transport at low doping concentrations and good confinement of the generated excitons within the CBP matrix. The poor electroluminescence performance of the devices with high doping concentrations may be attributed to the increased crystallinity, which could affect the thin-film surface morphology. ${ }^{31} \mathrm{~A}$ high turn-on voltage was observed for all the relevant devices, which could be explained in terms of the high energy barrier for the injection of charge carriers, utilization of only singlet excitons for emission due to the absence of triplet harvester rare-earth metals and significantly high energy gap between the singlet and triplet energy levels, poor surface morphology and high roughness of the solutionprocessed deposited thin films, and low charge carrier mobility of the designed molecules. Furthermore, the OLED devices based on the BIPTPA molecules displayed a relatively low turn-on voltage when compared with the OLED devices based on DBIPTPA and PBIPTPA. The reason behind this may be better charge balance in BIPTPA due to the presence of one donor and one acceptor. The molecules DBIPTPA and TBIPTPA consist of one hole transporting TPA and two and three imidazole-based electron-transporting units, respectively. The turn-on voltage of the resultant OLED devices can be further improved by adopting strategies reported in the literature. ${ }^{32}$

Notably, the $3 \mathrm{wt} \%$ DBIPTPA-based OLED device exhibited the best EL performance in the series with a maximum luminescence of $495 \mathrm{~cd} \mathrm{~m}^{-2}$, current efficiency (CE) of $0.7 \mathrm{~cd} \mathrm{~A}^{-1}$, power efficiency (PE) of $0.3 \mathrm{~lm} \mathrm{~W}^{-1}$, CIE coordinates of $(0.16,0.06)$, and EQE of 2.5\%, as shown in Fig. 10 and Table 4. Additionally, it displayed relatively low efficiency roll-off as compared to its counterparts. This may be attributed to the high quantum yield of the emitter material, balanced charge carrier within the emissive layer, efficient charge transport capabilities of the hole-transporting system triphenylamine and the electron-transporting system imidazole, appropriate energy level for charge injection, and suitable triplet energy to enable efficient host-to-guest energy transfer. Subsequently, the resultant device also showed $101 \%$ color saturation as compared with the NTSC standard (Fig. 12), which reveals its potential applications in high-quality flat panel displays.

The electroluminescence spectra of all the devices are displayed in Fig. 11. The EL spectra of all the non-doped devices slightly blue-shifted in comparison with the PL spectra of the corresponding amorphous films and those in solution state. This clearly indicates the formation of aggregates in the solid state, which in turn would induce crystallization owing to the 

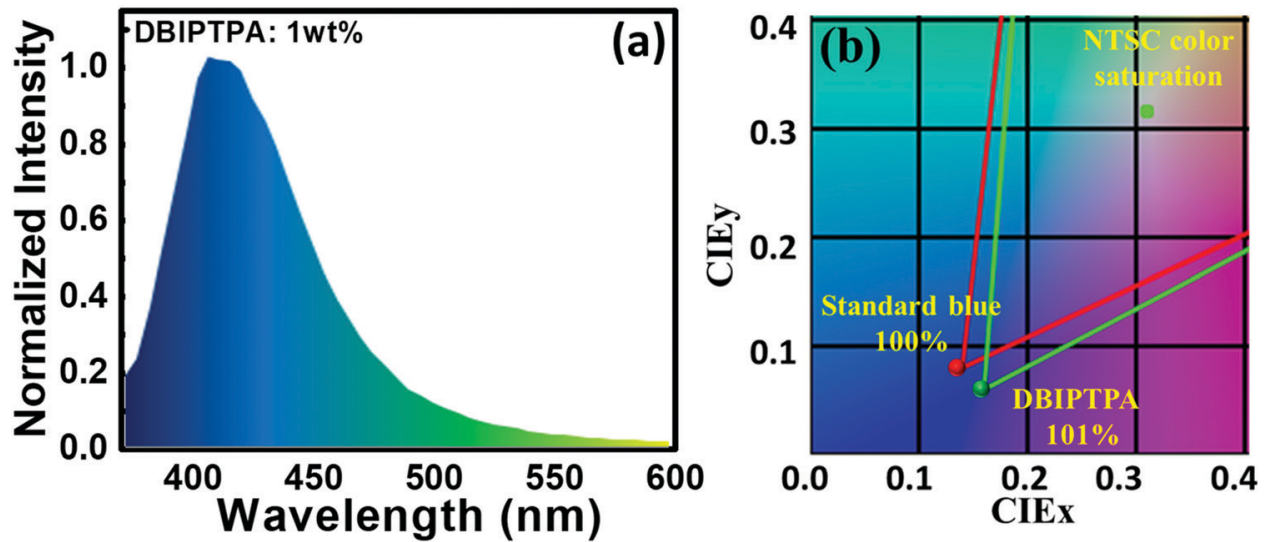

Fig. 12 (a and b) EL spectrum and NTSC color saturation of the solution-processed OLEDs containing 1 wt\% DBIPTPA as the emitter at the brightness of $100 \mathrm{~cd} \mathrm{~m}^{-2}$, respectively.

more twisted conformations between the peripheral imidazole moiety and the central TPA core in the synthesized compounds. Furthermore, the PL and EL spectra of BIPTPA and DBIPTA exhibited more blue-shifts as compared to those for TBIPTPA as a result of the different states of the packing order and the partial disruption of the prolonged conjugation. ${ }^{33}$ However, upon dilution in the CBP host, aggregation was prevented and thus, the molecular emission was reinstated. ${ }^{31}$ The BIPTPA and DBIPTPA-based doped devices displayed pure deep-blue emission with distinct peaks centered between 400 and $420 \mathrm{~nm}$ and the Commission International de l'E'clairage (CIE) coordinates of $0.16<x<0.17$ and $0.06<y<0.07$. The CIE coordinates of the doped devices were in good agreement with the standard pure deep-blue emission $(0.14,0.08)$, as specified by the National Television System Committee (NTSC). The TBIPTPA-based devices displayed sky-blue emission with the CIE coordinates of $(0.20 \pm 0.01,0.19 \pm 0.02)$ at $100 \mathrm{~cd} \mathrm{~m}^{-2}$. It is important to note that even with an increase in the doping concentration from 1 to $5 \mathrm{wt} \%$, the EL spectrum and CIE coordinates did not show any shifts or changes, suggesting that the designed emissive layer is aggregationresistant even at reasonably high molecular concentrations. Moreover, no CBP emission was observed in the EL spectra, manifesting complete energy transfer from the host to the guest. ${ }^{31}$

\section{Conclusion}

In summary, we have successfully designed and synthesized three deep blue donor-acceptor (D-A) luminophores. The synthesized luminophores showed good thermal stability and the photophysical properties were highly influenced by the substitution pattern of the imidazole moiety in the triphenylamine core. Red-shifts were observed in the emission profiles of one donor-two acceptor and one donor-three acceptor (DBIPTPA and TBIPTPA) luminophores compared to that of the one donor-one acceptor (BIPTPA) luminophore. Electrochemical analysis revealed that all the luminophores had distinct oxidation and reduction behaviors, which indicated their potential bipolar carrier transporting nature. These materials acted as pure deep-blue emitters in multi-layer solution-processed
OLEDs, which exhibited an EQE of $2.5 \%$ at $100 \mathrm{~cd} \mathrm{~m}^{-2}$ with the CIE coordinates of $(0.16,0.06)$, corresponding to pure blue light. The DBIPTPA-based device exhibited excellent EL performance with a maximum luminance of $495 \mathrm{~cd} \mathrm{~m}^{-2}$, external quantum efficiency of $2.5 \%$ and current efficiency of $0.8 \mathrm{~cd} \mathrm{~A}^{-1}$. This study might undeniably open new avenues for donor-acceptor luminophorebased electroluminescent materials with efficient deep-blueemitting OLEDs.

\section{Conflicts of interest}

There are no conflicts to declare.

\section{Acknowledgements}

VS acknowledges SERB, Department of Science and Technology (DST), India (EMR/2016/002462) for financial support.

\section{References}

1 (a) C. W. Tang and S. A. Van Slyke, Organic Electroluminescent Diodes, Appl. Phys. Lett., 1987, 57, 913-915; (b) Y. Shirota, Organic materials for electronic and optoelectronic devices, J. Mater. Chem., 2000, 10, 1-25; (c) S. R. Forrest, The path to ubiquitous and low-cost organic electronic appliances on plastic, Nature, 2004, 428, 911-918; (d) A. P. Kulkarni, C. J. Tonzola, A. Babel and S. A. Jenekhe, Solution-processable single-material molecular emitters for organic light-emitting devices, Chem. Mater., 2004, 16, 4556-4573; (e) M. A. Baldo, M. E. Thompson and S. R. Forrest, High-efficiency fluorescent organic light-emitting devices using a phosphorescent sensitizer, Nature, 2000, 403, 750-753; $(f)$ M. Zhu and C. Yang, Blue fluorescent emitters: design tactics and applications in organic light-emitting diodes, Chem. Soc. Rev., 2013, 42, 4963-4976; (g) X. H. Zhu, J. Peng, Y. Cao and J. Roncali, Solutionprocessable single-material molecular emitters for organic light-emitting devices, Chem. Soc. Rev., 2011, 40, 3509-3524. 
2 (a) B. C. Thompson and J. M. Frechet, Polymer-fullerene composite solar cells, Angew. Chem., Int. Ed., 2008, 47, 58-77; (b) A. Mishra, M. K. R. Fischer and P. Buerle, Metal-free organic dyes for dye-sensitized solar cells: from structure: property relationships to design rules, Angew. Chem., Int. Ed., 2009, 48, 2474-2499; (c) Y. Ooyama and Y. Harima, Molecular Designs and Syntheses of Organic Dyes for Dye-Sensitized Solar Cells, Eur. J. Org. Chem., 2009, 2903-2934.

3 (a) A. R. Murphy and J. M. Frechet, Organic Semiconducting Oligomers for Use in Thin Film Transistors, Chem. Rev., 2009, 107, 1066-1096; (b) M. M. Torrent and C. Rovira, Novel small molecules for organic field-effect transistors: towards processability and high performance, Chem. Soc. Rev., 2008, 37, 827-838; (c) C. Wang, H. Dong, W. Hu, Y. Liu and D. Zhu, Semiconducting $\pi$-Conjugated Systems in Field-Effect Transistors: A Material Odyssey of Organic Electronics, Chem. Rev., 2012, 112, 2208-2267.

4 (a) S. Kawata and Y. Kawata, Three-Dimensional Optical Data Storage Using Photochromic Materials, Chem. Rev., 2000, 100, 1777-1788; (b) M. Pawlicki, H. A. Collins, R. G. Denning and H. L. Anderson, Two-Photon Absorption and the Design of Two-Photon Dyes, Angew. Chem., Int. Ed., 2009, 48, 3244-3266; (c) G. S. He, L. S. Tan, Q. Zheng and P. N. Prasad, Multiphotonabsorbing materials: molecular designs, characterizations, and applications, Chem. Rev., 2008, 108, 1245-1330.

5 (a) Z. Xu, C. Liu, S. Zhao, S. Chen and Y. Zhao, Molecular Sensors for NMR-Based Detection, Chem. Rev., 2019, 119, 195-230; (b) H. C. Gee, C. Lee, Y. H. Jeang and W. D. Jang, Highly sensitive and selective cyanide detection via $\mathrm{Cu}^{2+}$ complex ligand exchange, Chem. Commun., 2011, 47, 11963-11965; (c) X. Xiong, F. Song, J. Wang, Y. Zhang, Y. Xue, L. Sun, N. Jiang, P. Gao, L. Tian and X. Peng, Thermally Activated Delayed Fluorescence of Fluorescein Derivative for Time-Resolved and Confocal Fluorescence Imaging, J. Am. Chem. Soc., 2014, 136, 9590-9597.

6 (a) T. Khanasa, N. Prachumrak, R. Rattanawan, S. Jungsuttiwong, T. Keawin, T. Sudyoadsuk, T. Tuntulani and V. Promarak, Bis(carbazol-9-ylphenyl)aniline End-Capped Oligoarylenes as Solution-Processed Nondoped Emitters for FullEmission Color Tuning Organic Light-Emitting Diodes, J. Org. Chem., 2013, 78, 6702-6713; (b) Y. Qiu, P. Wei, D. Q. Zhang, J. Qiao, L. Duan, Y. K. Li, Y. D. Gao and L. D. Wang, Novel Naphtho[2,3-c] $[1,2,5]$ thiadiazole Derivative for Non-doped Small Molecular Organic Red-Light-Emitting Diodes, Adv. Mater., 2006, 18, 1607-1611; (c) J. Huang, X. Qiao, Y. Xia, X. Zhu, D. Ma, Y. Cao and J. Roncali, A Dithienylbenzothiadiazole Pure Red Molecular Emitter with Electron Transport and Exciton Self-Confinement for Nondoped Organic Red-Light-Emitting Diodes, Adv. Mater., 2008, 20, 4172; (d) Y. Zhou, Q. He, Y. Yang, H. Zhong, C. He, G. Sang, W. Liu, C. Yang, F. Bai and Y. Li, Binaphthyl-Containing Green- and Red-Emitting Molecules for Solution-Processable Organic Light-Emitting Diodes, Adv. Funct. Mater., 2008, 18, 3299-3306.

7 (a) S. C. Lo and P. L. Burn, Development of Dendrimers: Macromolecules for Use in Organic Light-Emitting Diodes and
Solar Cells, Chem. Rev., 2007, 107, 1097-1116; (b) N. Prachumrak, S. Pojanasopa, S. Namuangruk, T. Kaewin, S. Jungsuttiwong, T. Sudyoadsuk and V. Promarak, Novel Bis[5-(fluoren-2yl)thiophen-2-yl]benzothiadiazole End-Capped with Carbazole Dendrons as Highly Efficient Solution-Processed Nondoped Red Emitters for Organic Light-Emitting Diodes, ACS Appl. Mater. Interfaces, 2013, 5, 8694-8703; (c) K. Bronk and S. Thayumanavan, Synthesis of NonconjugatedDendrons with a Redox Gradient, J. Org. Chem., 2003, 68, 5559-5567.

8 (a) A. C. Grimsdale, K. L. Chan, R. E. Martin, P. G. Jokisz and A. B. Holmes, Synthesis of Light-Emitting Conjugated Polymers for Applications in Electroluminescent Devices, Chem. Rev., 2009, 109(3), 897-1091; (b) J. H. Burroughes, D. D. C. Bradley, A. R. Brown, R. N. Marks, K. Mackay, R. H. Friend, P. L. Burn and A. B. Holmes, Light-emitting diodes based on conjugated polymers, Nature, 1990, 347, 539-541.

9 (a) B. W. D'Andrade and S. R. Forrest, White Organic LightEmitting Devices for Solid-State Lighting, Adv. Mater., 2004, 16, 1585-1595; (b) X. Qi, M. Slootsky and S. Forrest, Stacked white organic light emitting devices consisting of separate red, green, and blue elements, Appl. Phys. Lett., 2008, 93, 193306; (c) N. Chopra, J. Lee, Y. Zheng, S. H. Eom, J. Xue and F. So, High efficiency blue phosphorescent organic light-emitting device, Appl. Phys. Lett., 2008, 93, 143307.

10 (a) J.-H. Jou, Y.-M. Yang, S.-Z. Chen, J.-R. Tseng, S.-H. Peng, C.-Y. Hsieh, Y.-X. Lin, C.-L. Chin, J.-J. Shyue, S.-S. Sun, C.-T. Chen, C.-W. Wang, C.-C. Chen, S.-H. Lai and F.-C. Tung, High-Efficiency Wet- and Dry-Processed Green Organic Light Emitting Diodes with a Novel Iridium Complex-Based Emitter, Adv. Opt. Mater., 2013, 1, 657-667; (b) C.-H. Chen, L.-C. Hsu, P. Rajamalli, Y.-W. Chang, F.-I. Wu, C.-Y. Liao, M.-J. Chiu, P.-Y. Chou, M.-J. Huang, L.-K. Chu and C.-H. Cheng, Highly efficient orange and deep-red organic light emitting diodes with long operational lifetimes using carbazole-quinoline based bipolar host materials, J. Mater. Chem. C, 2014, 2, 6183-6191.

11 A. W. Grice, D. D. C. Bradley, M. T. Bernius, M. Inbasekaran, W. W. Wu and E. P. Woo, High brightness and efficiency blue light-emitting polymer diodes, Appl. Phys. Lett., 1998, 73, 629 .

12 (a) M. Zhu and C. Yang, Blue fluorescent emitters: design tactics and applications in organic light-emitting diodes, Chem. Soc. Rev., 2013, 42, 4963-4976; (b) W. Li, L. Yao, H. Liu, Z. Wang, S. Zhang, R. Xiao, H. Zhang, P. Lu, B. Yang and Y. Ma, Highly efficient deep-blue OLED with an extraordinarily narrow FHWM of $35 \mathrm{~nm}$ and a y coordinate $<0.05$ based on a fully twisting donor-acceptor molecule, J. Mater. Chem. C, 2014, 2, 4733-4736; (c) X. Yang, X. Xu and G. J. Zhou, Recent advances of the emitters for high performance deep-blue organic light-emitting diodes, J. Mater. Chem. C, 2015, 3, 919-944.

13 (a) R. J. Holmes, B. W. D'Andrade and S. R. Forrest, Efficient deep-blue organic electrophosphorescence by guest charge trapping, Appl. Phys. Lett., 2003, 83, 3818; (b) S. Thayumanavan, S. Barlow and S. R. Marder, Synthesis of Unsymmetrical 
Triarylamines for Photonic Applications via One-Pot PalladiumCatalyzedAminations, Chem. Mater., 1997, 9, 3231-3235; (c) M. Taneda, K. Shizu, H. Tanaka and C. Adachi, High efficiency thermally activated delayed fluorescence based on 1,3,5-tris(4-(diphenylamino)phenyl)-2,4,6-tricyanobenzene, Chem. Commun., 2015, 51, 5028-5031; (d) M. Liang and J. Chen, Arylamine organic dyes for dye-sensitized solar cells, Chem. Soc. Rev., 2013, 42, 3453-3488.

14 P. I. Shih, C. H. Chien, F. I. Wu and C. F. Shu, A Novel Fluorene-Triphenylamine Hybrid That is a Highly Efficient Host Material for Blue-, Green-, and Red-Light-Emitting Electrophosphorescent Devices, Adv. Funct. Mater., 2007, 17, 3514-3520.

15 L. Tao, J. Li, Y. Yu, Y. Jiang, C. S. Zhou, S. T. Lee, X. Zhang and O. Kwon, Bipolar Molecule as an Excellent HoleTransporter for Organic-Light Emitting Devices, Chem. Mater., 2009, 21, 1284-1287.

16 (a) Y. Zhang, S. L. Lai, Q. X. Tong, M. F. Lo, T. W. Ng, M. Y. Chan, Z. C. Wen, J. He, K. S. Jeff, X. L. Tang, W. M. Liu, C. C. Ko, P. F. Wang and C. S. Lee, High Efficiency Nondoped Deep-Blue Organic Light Emitting Devices Based on Imidazole- $\pi$-triphenylamine Derivatives, Chem. Mater., 2012, 24, 61-70; (b) W. Li, D. Liu, F. Shen, D. Ma, Z. Wang, T. Feng, Y. Xu, B. Yang and Y. Ma, A Twisting DonorAcceptor Molecule with an Intercrossed Excited State for Highly Efficient, Deep-Blue Electroluminescence, $A d v$. Funct. Mater., 2012, 22, 2797-2803; (c) X. Ouyang, X. L. Li, X. Zhang, A. Islam, Z. Ge and S. J. Su, Effective management of intramolecular charge transfer to obtain from blue to violet-blue OLEDs based on a couple of phenanthrene isomers, Dyes Pigm., 2015, 122, 264-271; (d) T. Jairam, H. Ulla, M. N. Satyanarayan and V. Sivakumar, Efficient non-doped bluish-green organic light emitting devices based on N1 functionalized star-shaped phenanthroimidazole fluorophores, J. Photochem. Photobiol., A, 2018, 353, 53-64; (e) T. Jairam, D. K. Dubey, J. H. Jou and V. Sivakumar, Near UV/Deep-blue phenanthroimidazole based luminophores for organic light emitting diodes: Experimental and theoretical investigation, ChemistrySelect, 2019, 4, 6458-6468.

17 M. Y. Lai, C. H. Chen, W. S. Huang, J. T. Lin, T. H. Ke, L. Y. Chen, M. H. Tsai and C. C. Wu, Benzimidazole/Amine-Based Compounds Capable of Ambipolar Transport for Application in Single-Layer Blue-Emitting OLEDs and as Hosts for Phosphorescent Emitters, Angew. Chem., Int. Ed., 2008, 47, 581-585.

18 (a) C. H. Yang, H. L. Chen, Y. Y. Chuang, C. G. Wu, C. P. Chen, S. H. Liao and T. L. Wang, Characteristics of triphenylamine-based dyes with multiple acceptors in application of dye-sensitized solar cells, J. Power Sources, 2009, 188, 627-634; (b) Y. X. Wang and M. K. Leung, $4,4^{\prime}, 4^{\prime \prime}$-Tris(acetoxymethylene)triphenylamine: An Efficient Photoacid Promoted Chemical Cross-Linker for Polyvinylcarbozole and Its Applications for Photolithographic HoleTransport Materials, Macromolecules, 2011, 44, 8771-8779.

19 (a) Y. Tao, Q. Wang, Y. Shang, C. Yang, L. Ao, J. Qin, D. Ma and Z. Shuai, Multifunctional bipolar triphenylamine/ oxadiazole derivatives: highly efficient blue fluorescence, red phosphorescence host and two-color based white OLEDs, Chem. Commun., 2009, 77-79; (b) Y. Tao, Q. Wang, L. Ao, C. Zhong, C. Yang, J. Qin and D. Ma, Highly Efficient Phosphorescent Organic Light-Emitting Diodes Hosted by 1,2,4-Triazole-Cored Triphenylamine Derivatives: Relationship between Structure and Optoelectronic Properties, J. Phys. Chem. C, 2010, 114, 601-609; (c) T. Jairam, H. Ulla, A. B. Kajjam, M. N. Satyanarayan and V. Sivakumar, Star-Shaped Phenanthroimidazole-Triphenylamine-Based Yellow Organic Emitter for Organic Light Emitting Diodes, ChemistrySelect, 2017, 2, 2611-2620.

20 W. C. Chen, Y. Yuan, G. F. Wu, H. X. Wei, J. Ye, M. Chen, F. Lu, Q. X. Tong, F. L. Wong and C. S. Lee, Molecular modification on bisphenanthroimidazole derivative for deepblue organic electroluminescent material with ambipolar property and high performance, Org. Electron., 2015, 17, 159.

21 G. Li, J. Zhao, D. Zhang, J. Zhu, Z. Shi, S. Tao, F. Lu and Q. Tong, Non-doped deep blue emitters based on twisted phenanthroimidazole derivatives for organic light-emitting devices ( $\left.\mathrm{CIE}_{y} \approx 0.04\right)$, New J. Chem., 2017, 25, 5191-5197.

22 P. Data, A. Kurowska, S. Pluczyk, P. Zassowski, P. Pander, R. Jedrysiak, M. Czwartosz, L. Otulakowski, J. Suwinski, M. Lapkowski and A. P. Monkman, Exciplex Enhancement as a Tool to Increase OLED Device Efficiency, J. Phys. Chem. C, 2016, 120, 2070-2078.

23 S. Jadoun, S. M. Ashraf and U. Riaz, Tuning the spectral, thermal and fluorescent properties of conjugated polymers via random copolymerization of hole transporting monomers, RSC Adv., 2017, 7, 32757-32768.

24 S. Ebraheem and A. E. Saied, Band Gap Determination from Diffuse Reflectance Measurements of Irradiated Lead Borate Glass System Doped with $\mathrm{TiO}_{2}$ by Using Diffuse Reflectance Technique Materials, Mater. Sci. Appl., 2013, 4, 324.

25 T. C. Lin, G. S. He, P. N. Prasad and L. S. Tan, Degenerate nonlinear absorption and optical power limiting properties of asymmetrically substituted stilbenoid chromophores, J. Mater. Chem., 2004, 14, 982-991.

26 (a) Y. S. Park, S. Lee, K. H. Kim, S. Y. Kim, J. H. Lee and J. J. Kim, Exciplex-Forming Co-host for Organic LightEmitting Diodes with Ultimate Efficiency, Adv. Funct. Mater., 2013, 23, 4914-4920; (b) J. Kalinowski, Excimers and exciplexes in organic electroluminescence, Mater. Sci.-Pol., 2009, 27, 735.

27 J. C. Mello, H. F. Wittmann and R. H. Friend, An improved experimental determination of external photoluminescence quantum efficiency, Adv. Mater., 1997, 9, 230-232.

28 (a) Y. Li, J. Ding, M. Day, Y. Tao, J. Lu and M. Diorio, Synthesis and Properties of Random and Alternating Fluorene/Carbazole Copolymers for Use in Blue Light-Emitting Devices, Chem. Mater., 2004, 16, 2165-2173; (b) Z. Zhao, X. Xu, Z. Jiang, P. Lu, G. Yu and Y. Liu, Oligo(2,7-fluorene ethynylene)s with Pyrene Moieties: Synthesis, Characterization, Photoluminescence, and Electroluminescence, J. Org. Chem., 2007, 72, 8345-8353.

29 M. J. Frisch, et al., Gaussian 09, Revision D.01, Gaussian, Inc., Wallingford CT, 2009. 
30 D. M. Leeuw, M. M. J. Simenon, A. R. Brown and R. E. F. Einerhand, Stability of n-type doped conducting polymers and consequences for polymeric microelectronic devices, Synth. Met., 1997, 87, 53-59.

31 (a) G. Valchanov, A. Ivanova, A. Tadjer, D. Chercka and M. Baumgarten, Tuning the optical absorption of potential blue emitters, Org. Electron., 2013, 14, 2727-2736; (b) D. Chercka, S. J. Yoo, M. Baumgarten, J. J. Kim and K. Mullen, Pyrene based materials for exceptionally deep blue OLEDs, J. Mater. Chem. C, 2014, 2, 9083-9086; (c) J. Y. Hu, Y. J. Pu, F. Satoh, S. Kawata, H. Katagiri, H. Sasabe and J. Kido, Bisanthracene-Based DonorAcceptor-type Light-Emitting Dopants: Highly Efficient DeepBlue Emission in Organic Light-Emitting Devices, Adv. Funct. Mater., 2014, 24, 2064; (d) J. H. Jou, Y. L. Chen, J. R. Tseng, R. Z. Wu, J. J. Shyue, K. R. J. Thomas, N. Kapoor, C. T. Chen, Y. P. Lin, P. H. Wang, H. W. Hung, J. Y. Lie and S. P. Chen, The use of a polarity matching and high-energy exciton generating host in fabricating efficient purplish-blue OLEDs from a sky-blue emitter, J. Mater. Chem., 2012, 22, 15500-15506; (e) J. H. Jou, S. Kumar, P. H. Fang, A. Venkateswararao, K. R. J. Thomas, J. J. Shyue, Y. C. Wang, T. H. Lia and H. H. Yu, Highly efficient ultra-deep blue organic light-emitting diodes with a wet- and dryprocess feasible cyanofluorene acetylene based emitter, J. Mater. Chem. C, 2015, 3, 2182-2194; ( $f$ ) C. W. Ko, Y. T. Tao, J. T. Lin and K. R. J. Thomas, Light-Emitting Diodes Based on a CarbazoleDerivatized Dopant: Origin of Dopant Excitation as a Function of the Device Structure, Chem. Mater., 2002, 14, 357-361; (g) G. Li, Y. Zhao, J. Li, J. Cao, J. Zhu, X. W. Sun and Q. Zhang, Synthesis, Characterization, Physical Properties, and OLED Application of Single BN-Fused PeryleneDiimide, J. Org. Chem., 2015, 80, 196-203; (h) R. K. Konidena, K. R. J. Thomas, S. Sahoo, D. K. Dubey and J. H. Jou, Multi-substituted deepblue emitting carbazoles: a comparative study on photophysical and electroluminescence characteristics, J. Mater. Chem. C, 2017, 5, 709; ( $i$ ) R. K. Konidena, K. R. J. Thomas, D. K. Dubey, S. Sahoo and J. H. Jou, A new molecular design based on hybridized local and charge transfer fluorescence for highly effcient (46\%) deep-blue organic light emitting diodes, Chem. Commun., 2017, 53, 11802-11805; ( $j$ ) S. Sahoo, D. K. Dubey, M. Singh, V. Joseph, K. R. J. Thomas and J. H. Jou, Highly efficient deep-blue organic light emitting diode with a carbazole based fluorescent emitter, Jpn. J. Appl. Phys., 2018, 57, 04FL08; (k) J. H. Jou, J. L. Li, S. Sahoo, D. K. Dubey, R. A. K. Yadav, V. Joseph, K. R. J. Thomas, C. W. Wang, J. Jayakumar and C. H. Cheng, Enabling a 6.5\% External Quantum Efficiency Deep-Blue Organic LightEmitting Diode with a Solution-Processable CarbazoleBased Emitter, J. Phys. Chem. C, 2018, 122, 24295-24303.

32 (a) Y. Miao, K. Wang, L. Gao, B. Zhao, H. Wang, F. Zhub, B. Xu and D. Ma, Precise manipulation of carrier recombination zone: a universal novel device structure for highly efficient monochrome and white phosphorescent organic light-emitting diodes with extremely small efficiency roll-off, J. Mater. Chem. C, 2018, 6, 8122-8134; (b) X. Wei, L. Gao, Y. Miao, Y. Zhao, M. Yin, H. Wang and B. Xua, A new strategy for structuring white organic lightemitting diodes by combining complementary emissions in the same interface, J. Mater. Chem. C, 2020, 8, 2772-2779; (c) P. Tao, Y. Miao, H. Wang, B. Xu and Q. Zhao, High-Performance Organic Electroluminescence: Design from Organic Light-Emitting Materials to Devices, Chem. Rec., 2019, 19, 1531-1561; (d) D. K. Dubey, S. Sahoo, C. W. Wang and J. H. Jou, Solution process feasible highly efficient white organic light emitting diode, Org. Electron., 2019, 69, 232-240; (e) J. H. Jou, S. Sahoo, D. K. Dubey, R. A. K. Yadav, S. S. Swayamprabha and S. D. Chavhan, Molecule-based monochromatic and polychromatic OLEDs with wet-process feasibility, J. Mater. Chem. C, 2018, 6, 11492-11518.

33 J. Huang, N. Sun, J. Yang, R. Tang, Q. Li, D. Ma, J. Qin and Z. Li, Benzene-cored fluorophors with TPE peripheries: facile synthesis, crystallization-induced blue-shifted emission, and efficient blue luminogens for non-doped OLEDs, J. Mater. Chem., 2012, 22, 12001-12007. 